\title{
STUDIES OF HYPOXEMIC/REOXYGENATION INJURY:
}

\section{Linkage between cardiac function and oxidant damage}

Gerald D. Buckberg, MD, Los Angeles, Calif.

$\mathrm{S}$ urgical correction of cardiac defects causing cyanosis is done with the use of cardiopulmonary bypass (CPB) in early infancy with increasing frequency. Postoperative cardiac dysfunction is the major cause of morbidity and mortality despite successful anatomic correction and is more severe than after repair of acquired defects in adults with normoxic conditions. ${ }^{1}$ Intraoperative management differs principally in that reversal of hypoxemia occurs with initiation of extracorporeal circulation and precedes the surgical ischemia used for operative repair in children with cyanotic disease.

The conventional method of starting CPB in infants and children with hypoxemia is to raise oxygen tension $\left(\mathrm{Po}_{2}\right)$ to approximately $400 \mathrm{~mm} \mathrm{Hg}$ by priming the extracorporeal circuit with hyperoxic fluid. We have speculated that this causes an "unintended reoxygenation injury" that adds to subsequent intraoperative stress when surgical ischemia is needed to provide a bloodless field. ${ }^{2}$ The role of reoxygenation injury as a contributory factor has yet to be established, despite experimental evidence that functional, biochemical, and structural alterations that follow reoxygenation are similar to changes that follow reperfusion after ischemia: these include stunned myocardium, ${ }^{3,4}$ lipid peroxidation, ${ }^{5}$ enzyme release, ${ }^{6}$ and necrosis. ${ }^{7}$ Several clinical observations support this hypothesis including (1) myocardial lipid peroxidation in preischemic right ventricular biopsy samples from children with cyanotic conditions supported by $\mathrm{CPB},{ }^{8}(2)$ reduced myocardial endogenous antioxidants in cyanotic versus normoxic patients, ${ }^{9}$ (3) strong correlation between $\mathrm{PO}_{2}$ and endogenous antioxidant enzymes, ${ }^{10}$

From the University of California at Los Angeles School of Medicine, Department of Surgery, Los Angeles, Calif.

Address for reprints: Gerald D. Buckberg, MD, UCLA Medical Center, Department of Surgery, Division of Cardiothoracic Surgery, B2-375 CHS, 10833 Le Conte Ave., Los Angeles, CA 90024-1741.

J Thorac Cardiovasc Surg 1995;110:1164-70

Copyright $\odot 1995$ by Mosby-Year Book, Inc.

$0022-5223 / 95 \$ 5.00+0 \quad \mathbf{1 2 / 0 / 6 1 6 9 3}$
(4) accentuated biochemical and functional damage in cyanotic versus noncyanotic patients despite shorter ischemia and comparable blood cardioplegia techniques, ${ }^{11}$ and (5) reduced systolic function in patients with cyanotic disease supported by extracorporeal membrane oxygenation because of respiratory failure, occasionally progressing to "cardiac stun" despite the absence of surgical ischemia. ${ }^{12,13}$

The normoxic immature myocardium has increased tolerance to ischemia because of adaptive mechanisms including increased glycolysis, ${ }^{14}$ substrate level phosphorylation, ${ }^{15}$ low $5^{\prime}$-nucleotidase levels, ${ }^{16}$ and increased mitochondrial activity. ${ }^{17}$ These adaptations notwithstanding, cyanotic adult and immature hearts are less tolerant to intraoperative ischemia than normoxic hearts. ${ }^{11,18,19}$ Reactive oxygen intermediates are the common denominator that mediate reperfusion/reoxygenation injury, and superoxide anion $\left(\mathrm{O}_{2}{ }^{-}\right)$may be a central effector in this damage, especially because reoxygenation is associated with a burst of superoxide anion $\left(\mathrm{O}_{2}{ }^{-}\right)^{20}$ and $\mathrm{CPB}$ per se may generate reactive oxygen intermediates by altering neutrophils, ${ }^{21} \mathrm{com}$ plement, ${ }^{22}$ and arachidonic acid metabolism. ${ }^{23}$ Normally, organs contain ubiquitous endogenous oxygen radical scavengers (i.e., superoxide dismutase, catalase, reduced glutathione, tocopherol, and vita$\min C$ ) that counteract the effects of toxic oxygen species (hydrogen peroxide, $\mathrm{H}_{2} \mathrm{O}_{2}$, and hydroxyl radical, $\mathrm{OH} \cdot$ ). Hypoxia ${ }^{5,24}$ and/or ischemia ${ }^{25}$ deplete tissue levels of these naturally occurring barriers to oxidant damage and increase vulnerability to reoxygenation injury, especially because reoxygenation causes further reduction of antioxidants. ${ }^{5}$

Reoxygenation injury affects tissue other than the myocardium ${ }^{26}$ and occurs without the confounding influence of CPB. For example, studies of lung reoxygenation show that pretreatment with oxygen radical scavengers ${ }^{27}$ limits the pulmonary injury that follows reexpansion after chronic atelectasis. Additionally, vascular endothelium is a well-recognized target after reintroduction of molecular oxygen, because reperfusion reduces coronary endothelial nitric oxide $(\cdot \mathrm{NO})$ production and subsequent endo- 
thelial dependent relaxation and potentiates endothelial-derived contraction to favor coronary vasospasm. ${ }^{28}$ A similar change may occur in the lung ${ }^{27}$ so that the impaired capacity to produce endogenous -NO favors pulmonary vasoconstriction ${ }^{29}$ and exogenous NO delivery may be required to reduce pulmonary vascular resistance. ${ }^{30}$

Reoxygenated human and bovine endothelial cells release superoxide anion $\left(\mathrm{O}_{2}{ }^{-}\right)$and become potent generators of $\cdot \mathrm{OH}$, causing lipid peroxidation, protein sulfhydryl oxidation, and cross-linking, which leads to enzyme activation with ultimate extravasation of intravascular components, signifying alteration of barrier function. ${ }^{31}$ Early endothelial cell membrane injury also promotes subsequent neutrophil adherence and activation, leading to capillary plugging, reduced flow, and release of oxidants (i.e., $\mathrm{O}_{2}{ }^{-}$) that may cause myocardial stunning, ${ }^{32}$ with the global effect of causing the low output syndrome.

Classically, reactive oxygen species mediate reperfusion/reoxygenation injury via the Haber-Weiss (Fenton) pathway. An alternative explanation was proposed recently by Beckman and associates ${ }^{33}$ whereby superoxide anion $\left(\mathrm{O}_{2}{ }^{-}\right)$and $\cdot \mathrm{NO}$ react to form a cytotoxic $\mathrm{O}_{2}$ species. Recent studies show that reoxygenation of cyanotic infantile hearts supported by $\mathrm{CPB}$ is associated with a burst of $\cdot \mathrm{NO}$ that correlates with oxidant damage and myocardial dysfunction, which could be limited by either adding -NO synthase inhibitors or antioxidants to the priming solution of the $\mathrm{CPB}$ circuit. $^{2} \cdot \mathrm{NO}$ also mediates release of iron from ferritin, heme, and nonheme proteins, ${ }^{34}$ and iron content rises eightfold to ninefold after reoxygenation ${ }^{35}$ to become available to react with hydrogen peroxide. Thus NO may participate in the Haber-Weiss reaction, but by mechanisms not appreciated previously, inasmuch as the role of $\cdot \mathrm{NO}$ in the reperfusion/reoxygenation process is emerging as ongoing research uncovers new actions of this substance. Deferoxamine is an iron chelator that limits reperfusion-related damage, ${ }^{36}$ but its precise mechanism of action in inhibiting metal-mediated oxidant injury is only now beginning to be revealed.

The possibility exists, therefore, that there is a -NO paradox, like the $\mathrm{O}_{2}$ and calcium paradox, ${ }^{37}$ whereby a substance responsible for modulating normal physiologic functions (i.e., mediating vasodilation and reducing white blood cell margination and migration through the vessel wall and platelet adhesiveness, and so on) may become deleterious when produced in high concentrations on reoxygenation. The confusion over how the same substance can be both salutary and detrimental is resolved by recognizing that it may have different actions during and after reoxygenation. A similar apparent dichotomy occurs with calcium, which accentuates reperfusion injury immediately after restoring coronary blood flow after ischemia, yet is needed in normal or increased concentrations to modulate cardiac contractile capacity when CPB is discontinued.

This manuscript introduces a series of studies of reoxygenation injury in the immature cyanotic myocardium that (1) show that damage is, in part, iatrogenic and can be modified by altering the management of CPB, (2) explore the mechanisms of reoxygenation injury, (3) define markers of damage, and (4) test various treatment protocols directed at its avoidance. Extrapolation of experimental findings to clinical events requires a reasonable perspective of the limitations of laboratory methods.

\section{Experimental models}

In vitro models of hypoxia/reoxygenation confirm the occurrence of $\mathrm{O}_{2}$-mediated damage, ${ }^{5,24}$ but such models (1) preclude the evaluation of noncardiac effects of interventions (i.e., on pancreas and lung), (2) exclude neuroendocrine influences, (3) are applicable only in studies of transplantation or circulatory arrest because they are devoid of noncoronary collateral flow that washes out any cardioplegic solution used to limit surgical ischemic damage, (4) produce results that vary, depending on the perfusion medium, ${ }^{38}$ and (5) may inadvertently combine hypoxia and ischemia, inasmuch as coronary blood flow is fixed and coronary perfusion pressure falls during hypoxic vasodilation. ${ }^{39} \mathrm{~A}$ similar hypoxic/ ischemic insult may occur in the acute in vivo ventilator hypoxia model, because reduced inspired oxygen produces asphyxia, which may be associated with acidosis and hemodynamic deterioration, which does not occur in patients with chronic compensated cyanosis. ${ }^{40}$ The in vivo model does, however, retain neuroendocrine influences, a physiologic perfusate (blood), and noncoronary collateral flow and permits determination of noncardiac effects of various interventions, thereby allowing extrapolation of experimental results to the clinical setting.

An in vivo model of hypoxia and reoxygenation with the use of CPB will be introduced in some studies to overcome the shortcomings of hemodynamic deterioration with ventilator hypoxia, but no short-term model allows development of the adap- 


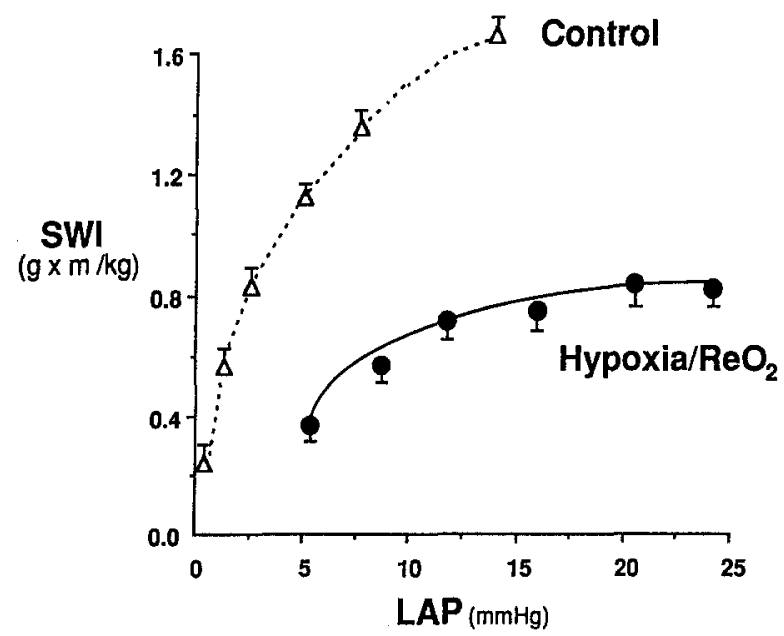

Fig. 1. Cardiac functional reserve capacity evaluated by testing myocardial performance by volume infusion in nonhypoxemic (control) piglets and after 2 hours of hypoxia followed by reoxygenation $\left(\mathrm{ReO}_{2}\right)$ during CPB. $S W I$, Stroke work index; $L A P$, left atrial pressure.

tive metabolic mechanisms to chronic hypoxemia that occur in patients with cyanotic conditions who undergo cardiac correction. Despite this, studies of chronically cyanotic neonatal lambs ${ }^{18}$ and adult $\operatorname{dogs}{ }^{19}$ confirm the decreased ischemic tolerance of the cyanotic heart that characterizes acute hypoxia studies, and this decreased ischemic tolerance has been confirmed clinically. ${ }^{11}$ Unfortunately, few studies of chronic hypoxia have been reported because of high perioperative mortality and consequent expenditure of personnel and monetary cost for chronic care. Furthermore, chronically cyanotic hearts develop cardiac hypertrophy, which may confound results, ${ }^{19}$ and, more important, they are always subjected to reoxygenation before testing of various cardioprotective strategies, so that the role of reoxygenation per se remains unexplored.

\section{Reserve capacity and subsequent stress}

Several methods to evaluate functional and biochemical effects of hypoxia and reoxygenation are available for study, and it seemed appropriate to place these into clinical perspective to emphasize the importance of evaluating reserve capacity in interpreting the effects of various interventions. The two measurements of myocardial reserve capacity made routinely in experimental studies and in clinical practice are the vasodilator and myocardial functional reserve capacity to provide insight into the capacity of the heart to either augment or maintain flow or function as demands for coronary blood flow or cardiac work increase. A third measurement, the antioxidant reserve capacity, is less well recognized, but has analogous implications because vulnerability to oxidant damage increases as endogenous stores of naturally occurring antioxidant defenses become depleted.

Coronary vasodilator reserve capacity. We did not test coronary vasodilator reserve capacity in these studies, but mention it because this is a relevant and familiar experimental and clinical measurement that evaluates both the resting and potential response to stress. Patients with coronary disease expend vasodilator reserve capacity to maintain flow beyond stenosis under resting conditions and ischemia develops when flow cannot be augmented further when the patients are stressed by treadmill testing.

Myocardial functional reserve capacity. Cardiac contractile functional reserve capacity is evaluated clinically by assessment of response to volume infusion, whereby fiber stretch (preload) lengthens and cardiac output and blood pressure rise during transfusion per Starling's law of the heart (Fig. 1). Physiologists question this method of functional assessment because of the dependency of loading conditions and heart rate. ${ }^{41}$ The availability of sophisticated methods (i.e., conductance catheters, ultrasonic crystals, gated imaging methods) allows an instantaneous assessment of contractility in the laboratory setting through calculation of end-systolic elastance or preload recruitable stroke work, or both. ${ }^{42}$ These methods also have limitations ${ }^{43}$ and are unavailable in routine clinical practice where the only evidence of depression is the need for a higher filling pressure (i.e., greater than $15 \mathrm{~mm} \mathrm{Hg}$ left atrial pressure, greater than $10 \mathrm{~mm} \mathrm{Hg}$ right atrial pressure) to achieve a normal cardiac index. This usual clinical endpoint of a "normal cardiac index" is at the bottom of the Starling curve (Fig. 1) and myocardial functional reserve capacity is tested rarely beyond this point. Conversely, functional reserve capacity is tested routinely in experimental studies by varying preload by inferior vena caval occlusion or transfusion to supernormal cardiac indices; the inability to recruit increased contractile force is reported as the degree of functional depression. This functional impairment may not be apparent readily from the bedside, aside from increased filling pressures, so that there is a natural tendency 
to ascribe experimentally demonstrated functional depression to the artificiality of a laboratory setting (where function is actually tested) and to reject its occurrence clinically (where it is not tested) other than to increase volume loading to determine whether cardiac index reaches "normal levels." Encroachment on clinical functional reserve capacity becomes obvious when hearts with negligible reserve capacity undergo further contractile impairment when cardioprotective strategies are imperfect. Under these conditions, the requirement for inotropic drugs become routine, and mechanical circulatory support is sometimes needed (intraaortic balloon or. left- or right-sided ventricular assist devices). Conversely, a similar intraoperative insult is tolerated well by hearts with normal reserve capacity and impairment becomes evident only by a mild to moderate increased filling pressure to achieve a normal cardiac index or by minimum need for temporary inotropic support.

Antioxidant reserve capacity. A third measurement of functional reserve capacity is the antioxidant reserve capacity. This is assessed in vitro by incubating cardiac muscle in varying concentrations of a standard oxidant and evaluating the extent of cardiac lipid peroxidation by malondialdehyde elaboration (Fig. 2). The dose response is remarkably similar to the effects of volume loading during inscription of Starling function curves shown in Fig. 1 and there is close linkage between antioxidant depletion, oxidant damage, and cardiac dysfunction. The biochemical consequence of antioxidant depletion is more malondialdehyde generation after exposure to a standard oxidant stimulus; the functional consequence is myocardial stunning characterized by lower stroke index at similar left atrial pressures. ${ }^{3}$ The clinical counterpart to this in vitro determination is increased vulnerability of previously ischemic or hypoxic tissue to damage after application of similar surgical stress (i.e., a fixed duration of aortic clamping). Normal hearts with abundant antioxidant reserve capacity develop only minor functional impairment after a standard ischemic challenge, whereas hearts with limited antioxidant reserve capacity exhibit more marked contractile depression. These observations explain also why pretreatment with antioxidants increases ischemic tolerance. $^{44}$

\section{Markers of oxidant damage}

The most commonly measured and widely used markers of oxidant injury are conjugated dienes and

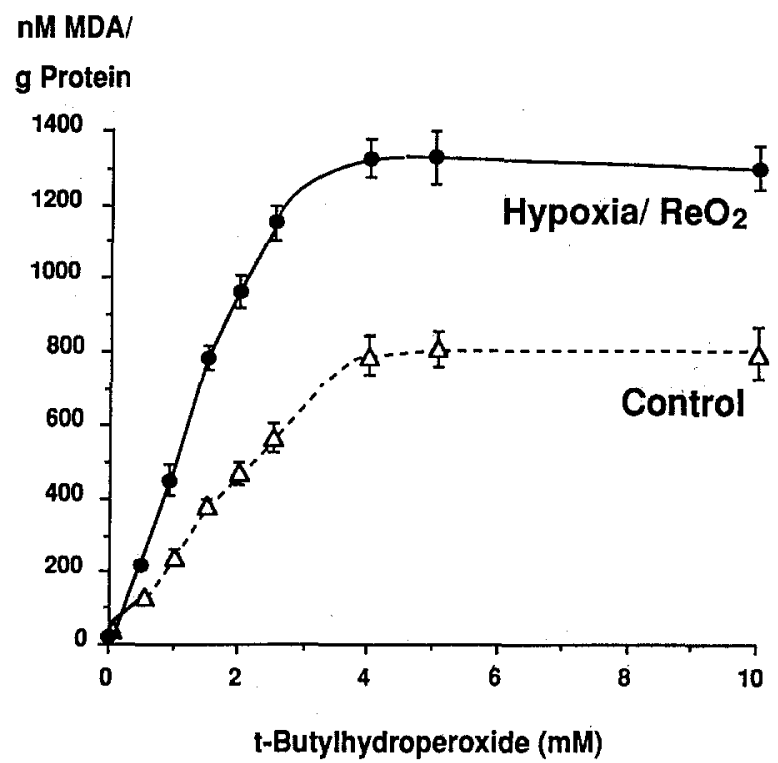

Fig. 2. Antioxidant reserve capacity evaluated before hypoxemia and after 2 hours of hypoxemia and reoxygenation $\left(\mathrm{ReO}_{2}\right)$ during CBP.

malondialdehyde. Tissue is not usually available to test oxidative reserve capacity but elution of conjugated dienes or thiobarbituric acid-related substances to detect malondialdehyde is generally regarded as quantifying lipid peroxidation; these may also indicate a more generalized tissue insult because they reflect also oxidant damage to carbohydrates, proteins, amino acids, and deoxyribonucleic acid rather than lipids alone, as well as products generated during the acid heating stage of the test. ${ }^{45}$ More recent data suggest that oxidant stress causes also a loss of protein sulfhydryls and rise in protein carbonyl derivatives, and specific methods are becoming available for analysis of uric acid, ${ }^{46}$ ascorbate-dehydroscorbate, ${ }^{47}$ and reduced/oxygenized tocopherol $^{47}$ to provide insight into the precise type of antioxidant that is depleted, as well as the target site on membrane or cytosol where oxidant damage occurs. These more precise markers of oxidant stress notwithstanding, measurements of tissue and transmyocardial conjugated dienes and tissue antioxidant reserve capacity remain useful tools to (1) detect the occurrence of oxidant damage and (2) determine the status of endogenous antioxidant defense capacity. There is an inverse relationship between antioxidant reserve capacity and conjugated diene elaboration. As oxidant damage increases, endogenous antioxidant reserve capacity becomes depleted (Fig. 2). 


\section{Current studies}

Using the aforementioned markers of oxidant damage, antioxidant reserve capacity, and functional resérve capacity, we will report a series of studies (1) providing evidence of reoxygenation injury with ventilator hypoxia and reoxygenation by either the ventilator or $\mathrm{CPB}$; we will introduce also a new model of hypoxia and reoxygenation during CPB that avoids the hemodynamic deterioration that characterizes ventilator hypoxia, (2) comparing similar intervals of hypoxia/reoxygenation with ischemia/reperfusion and showing hypoxia/reoxygenation is more deleterious, (3) examining the roles of the iron-related and L-arginine-nitric oxide pathways in reoxygenation damage, (4) describing in vivo and in vitro studies of the antioxidants $N$-(2-mercaptopropionyl)-glycine, catalase, and coenzyme $\mathrm{Q}_{10}$ and deferoxamine showing how and why adding them to the prime of the extracorporeal circuit limits damage, (5) demonstrating that reoxygenation injury interferes with the cardioprotective effects of blood cardioplegia and that this is reversed by antioxidants, (6) assessing the role of amino acid supplementation in the extracorporeal circuit priming solution, (7) determining the effects of lowering $\mathrm{PO}_{2}$ at the initiation of $\mathrm{CPB}$ and demonstrating that abrupt versus gradual reoxygenation is ineffective without other treatment protocols, (8) introducing the concept of controlled cardiac reoxygenation whereby reoxygenation is delayed until the blood cardioplegic solution is delivered, (9) defining the role of individual components of the blood cardioplegic solution in limiting $\cdot$ NO-mediated cardiac damage, and (10) questioning the need to ever use hyperoxic management in cyanotic infants and suggesting that avoidance of hyperoxia is analogous to restricting inspired oxygen fraction in newborn infants to avoid retrolental fibroplasia.

I anticipate that this series of studies will lead to the conclusion that reoxygenation injury is a real source of postoperative cardiac dysfunction that can be modified and possibly ameliorated by a change in intraoperative management during initiation of $\mathrm{CPB}$ in children with cyanotic disease. It is hoped that the studies will provide a basis for developing strategies that increase the safety of extracorporeal circulation in infants with cyanotic disease and serve as a stimulus to subsequent studies of how modification of reoxygenation damage may lead to improved results during surgical repair of congenital defects causing cyanosis.

\section{REFERENCES}

1. Kirklin JK, Blackštone EH, Kirklin JW, McKay R, Pacifico AD, Bargếron LMJ. Intracardiac surgery in infants under age 3 months: incremental risk factors for hospital mortality. Äm J Cardiol 1981;48:500-6.

2. Matheis G, Sherman MP, Buckberg GD, Haybron DM, Young HH, Ignarro LJ. Role of L-arginine-nitric oxide pathway in myocardial reoxygenation injury. Am J Physiol 1992;262:H616-20.

3. Kraemer R, Mullane KM. Neutrophils delay functional recovery of the post-hypoxic heart of the rabbit. J Pharmacol Exp Ther 1989;251:620-6.

4. Samaja M, Motterlini R, Santoro F, Dell'Antonio G, Como A. Oxidative injury in reoxygenated and reperfused hearts. Free Radic Biol Med 1994;16:255-62.

5. Guarnieri C, Flamigni F, Caldarera CM. Role of oxygen in the cellular damage induced by reoxygenation of hypoxic heart. J Mol Cell Cardiol 1980;12: 797-808.

6. Hearse DJ, Humphrey SM, Chain EB. Abrupt reoxygenation of the anoxic potassium-arrested perfused rat heart: a study of myocardial enzyme release. J Mol Cell Cardiol 1973;5:395-407.

7. Hearse DJ, Humphrey SM, Nayler WG, Slade A, Border D. Ultrastructural damage associated with reoxygenation of the anoxic myocardium. J Mol Cell Catdiol 1975;7:315-24.

8. Del Nido PJ, Mickle DAG, Wilson GJ, et al. Evidence of myocardial free radical injury during elective repair of tetralogy of Fallot. Circulation 1987;76(suppl): V174-9.

9. Teoh KH, Mickle DAG, Weisel RD, et al. Effect of oxygen tension and cardiovascular operations on the myocardial antioxidant enzyme activities in patients with tetralogy of Fallot and aorta-coronary bypass. $\mathbf{J}$ Thorac Cardiovasc Surg 1992;104:159-64.

10. Li K, Mickle DAG, Weisel RD, et al. Effect of oxygen tension on the anti-oxidant enzyme activities of tetralogy of Fallot ventricular myocytes. J Mol Cell Cardiol 1989;21:567-75.

11. Del Nido PJ, Mickle DAG, Wilson GJ, et al. Inadequate myocardial protection with cold cardioplegic arrest during repair of tetralogy of Fallot. J THORAC Cardiovasc SuRg 1988;95:223-9.

12. Hirschl RB, Heiss KF, Bartlett RH. Severe myocardial dysfunction during extracorporeal membrane oxygenation. J Pediatr Surg 1992;27:48-53.

13. Martin GR, Short BL, Abbott C, O'Brien A. Cardiac stun in infants undergoing extracorporeal membrane oxygenation. J THORAC CARDIOVASC SURG 1991;101: $607-11$.

14. Jarmakani JM, Nagatomo T, Nakazawa M, Langer GA. Effect of hypoxia on myocardial high-energy phosphates in the neonatal mammalian heart. Am $\mathbf{J}$ Physiol 1978;235: H475-81.

15. Julia PL, Young HH, Buckberg GD, Kofsky ER, Bugyi HI. Studies of myocardial protection in the 
immature heart. II. Evidence for importance of amino acid metabolism in tolerance to ischemia. $\mathrm{J}$ THORAC Cardiovasc Surg 1990;100:888-95.

16. Bolling SF, Olszanski DA, Bove EL, Childs KF. Enhanced myocardial protection during global ischemia with 5 -nucleotidase inhibitors. J THORAC CARDIOVASC Surg 1992;103:73-7.

17. Park CD, Mela L, Wharton R, Reilly J, Fishbein P, Aberdeen E. Cardiac mitochondrial activity in acute and chronic cyanosis. J Surg Res 1973;14:139-46.

18. Fujiwara T, Kurtts T, Anderson W, Heinle J, Mayer JEJ. Myocardial protection in cyanotic neonatal lambs. J Thorac Cardiovasc Surg 1988;96:700-10.

19. Silverman NA, Kohler J, Levitsky S, Pavel DG, Fang RB, Feinberg H. Chronic hypoxemia depresses global ventricular function and predisposes to depletion of high energy phosphates during cardioplegic arrest: implications for surgical repair of cyanotic congenital heart defects. Ann Thorac Surg 1984;37:304-8.

20. Bolli R, Jeroudi MO, Patel BS. Direct evidence that oxygen-derived free radicals contribute to postischemic myocardial dysfunction in the intact dog. Proc Natl Acad Sci 1989;86:4695-9.

21. Bando K, Pillai R, Cameron DE, et al. Leukocyte depletion ameliorates free radical-mediated lung injury after cardiopulmonary bypass. J THORAC CARDIOvASC SURG 1990;99:873-7.

22. Cavarocchi NC, England $\mathrm{MD}$, Schaff $\mathrm{HV}$, et al. Oxygen free radical generation during cardiopulmonary bypass: correlation with complement activation. Circulation 1986;74(Suppl):III130-3.

23. Greeley WJ, Bushman GA, Kong DL, Oldham HN, Peterson MB. Effect of cardiopulmonary bypass on eicosanoid metabolism during pediatric cardiovascular surgery. J Thorac Cardiovasc Surg 1988;95: 842-9.

24. Gauduel Y, Duvelleroy MA. Role of oxygen radicals in cardiac injury due to reoxygenation. $\mathbf{J}$ Mol Cell Cardiol 1984;16:459-70.

25. Ferrari R, Ceconi C, Curello S, et al. Oxygen-mediated myocardial damage during ischaemia and reperfusion: role of the cellular defences against oxygen toxicity. J Mol Cell Cardiol 1985;17:937-45.

26. Jackson RM, Veal CF. Review: re-expansion, reoxygenation, and rethinking. Am J Med Sci 1989;298: 44-50.

27. Jackson RM, Veal CF, Beckman JS, Brannen AL. Polyethylene glucol-conjugated superoxide dismutase in unilateral lung injury due to re-expansion (reoxygenation). Am J Med Sci 1990;300:22-8.

28. VanBenthuysen KM, McMurtry IF, Horwitz LD. Reperfusion after acute coronary occlusion in dogs impairs endothelium-dependent relaxation to acetylcholine and augments contractile reactivity in vitro. $\mathrm{J}$ Clin Invest 1987;79:265-74.

29. Haybron DM, Matheis GF, Buckberg GD, Sherman
MP, Byrns R, Ignarro LJ. Hypoxic pulmonary hypertension in the neonatal piglet is related to decreased intravascular endothelium-derived nitric oxide. Surg Forum 1991:42:285-7.

30. Pepke-Zaba J, Higenbottam TW, Tuan Dinh-Xuan A, Stone D, Wallwork J. Inhaled nitric oxide as a cause of selective pulmonary vasodilatation in pulmonary hypertension. Lancet 1991;338:1173-4.

31. Zweier JL, Kuppusamy P, Lutty GA. Measurement of endothelial cell free radical generation: evidence for a central mechanism of free radical injury in postischemic tissues. Proc Natl Acad Sci 1988;85:4046-50.

32. Engler RL, Schmid-Schonbein GW, Pavelec RS. Leukocyte capillary plugging in myocardial ischemia and reperfusion in the dog. Am J Pathol 1983;111:98-111.

33. Beckman JS, Beckman TW, Chen J, Marshall PA, Freeman BA. Apparent hydroxyl radical production by peroxynitrite: implications for endothelial injury from nitric oxide and superoxide. Proc Natl Acad Sci 1990;87:1620-4.

34. Reif DW, Simmons RD. Nitric oxide mediates iron release from ferritin. Arch Biochem Biophys 1990; 283:537-41.

35. Chevion M, Jiang Y, Har-El R, Berenshtein E, Uretzky G, Kitrossky N. Copper and iron are mobilized following myocardial ischemia: possible predictive criteria for tissue injury. Proc Natl Acad Sci 1993;90:1102-6.

36. Bolli R, Patel BS, Jeroudi MO, et al. Iron-mediated radical reactions upon reperfusion contribute to myocardial "stunning." Am J Physiol 1990;259:H1901-11.

37. Hearse DJ, Humphrey SM, Bullock GR. The oxygen paradox and the calcium paradox: two facets of the same problem? J Mol Cell Cardiol 1978;10:641-68.

38. Walters HLI, Digerness SB, Naftel DC, Waggoner JRI, Blackstone FH, Kirklin JW. The response to ischaemia in blood perfused vs. crystalloid perfused isolated rat heart preparations. J Mol Cell Cardiol 1992;24:1063-77.

39. Gillespie MN, Kojima S, Owasoyo JO, Tai HH, Jay M. Hypoxia provokes leukotriene-dependent neutrophil sequestration in perfused rabbit hearts. J Pharmacol Exp Ther 1987;241:812-6.

40. Rudolph W. Myocardial metabolism in cyanotic congenital heart disease. Cardiology 1971;56:209-15.

41. Glower DD, Spratt JA, Snow ND, et al. Linearity of the Frank-Starling relationship in the intact heart: the concept of preload recruitable stroke work. Circulation 1985;71:994-1009.

42. Little WC, Cheng C, Mumma M, Igarashi Y, VintenJohansen J, Johnston WE. Comparison of measures of left ventricular contractile performance derived from pressure-volume loops in conscious dogs. Circulation 1989;80:1378-87.

43. Buckberg GD, Hoffman JIE. The search for independence in a dependent world: myocardial contractili- 
ty-the physiologic equivalent of the philospher's stone. J ThORAC Cardiovasc Surg 1989;98:792-5.

44. Julia PL, Young HH, Buckberg GD, Kofsky ER, Bugyi HI. Studies of myocardial protection in the immature heart: IV. Improved tolerance of immature myocardium to hypoxia and ischemia by intravenous metabolic support. J ThoraC CARdIOVASC SURG 1991; 101:23-32.

45. Radi R, Bush KM, Cosgrove TP, Freeman BA. Reaction of xanthine oxidase-derived oxidants with lipid and protein of human plasima. Arch Biochem Biophys 1991;286:117-25.

46. Kaur H, Halliwell B. Action of biologically-relevant oxidizing species upon uric acid: identification of uric acid oxidation products. Chem Biol Interact 1990;73: 235-47.

47. Lemke M, Frei B, Ames BN, Faden AI. Decreases in tissue levels of ubiquinol-9 and -10 , ascorbate and $\alpha$-tocopherol following spinal cord impact trauma in rats. Neurosci Lett 1990;108:201-6. 